\title{
PENDAMPINGAN KELUARGA DALAM MENINGKATKAN KUALITAS HIDUP ANAK BERKEBUTUHAN KHUSUS DI WILAYAH KELURAHAN TALAGASARI KECAMATAN KAWALU KOTA TASIKMALAYA
}

\author{
Lia Herliana ${ }^{1}$, Betty Suprapti ${ }^{2}$, Dewi Aryanti ${ }^{3}$ \\ ${ }^{122) 3)}$ Program Studi DIII Keperawatan Tasikmalaya
}

\author{
liaherliana3@gmail.com
}

\begin{abstract}
Children with disabilities or children with special needs are children who have limitations both physically and mentally. In the view of society, children with special needs are known as people with disabilities (Law No. 4 of 1977) but the term contains negative connotations. International commitment to building a more inclusive society has resulted in the situation of children with disabilities and their families who continue to face obstacles to participate in civil, social and cultural problems in their communities. These efforts are carried out by implementing the fight against discrimination and increasing awareness of disability among the general public, eliminating obstacles to inclusion so that all children's environments - schools, health facilities, public transportation can facilitate access and encourage the participation of children with disabilities together with their colleagues. The activities that will be carried out in the partnership program with the community are by providing assistance to families who have children with disabilities by providing health education so that children always feel valuable and have a positive meaning, as well as detecting growth and periodic health checks for children with disabilities .
\end{abstract}

Keywords: children with disabilities, mentoring, growth and development

\begin{abstract}
ABSTRAK
Anak disabilitas atau anak berkebutuhan khusus adalah anak yang mempunyai keterbatasan baik secara fisik maupun mental intelektual. Dalam pandangan masyarakat, anak berkebutuhan khusus dikenal dengan istilah penyandang cacat (UU No 4 Tahun 1977) tetapi istilah itu mengandung konotasi yang negative. Komitmen internasional untuk membangun masyarakat yang lebih inklusi telah menghasilkan situasi anak penyandang disabilitas dan keluarga mereka yang masih terus menghadapi rintangan untuk berpartisipasi dalam masalah-masalah sipil, social dan budaya di masyarakat mereka. Upaya-upaya tersebut dilakukan salah satunya dengan implementasi memerangi diskriminasi dan meningkatkan kesadaran akan disabilitas di kalangan masyarakat umum, menghilangkan rintangan-rintangan terhadap inklusi sehingga seluruh lingkungan anak - sekolah, fasilitas kesehatan, transfortasi public bisa memfasilitasi akses dan mendorong partisipasi anak penyandang disabilitas bersama dengan rekan-rekan mereka. Kegiatan yang akan dilakukan dalam melakukan program kemitraan dengan masyarakat ini adalah dengan melakukan pendampingan pada keluarga yang memiliki anak disabilitas dengan memberikan pendidikan kesehatan agar anak senantiasa merasa berharga dan memiliki arti yang positif, serta melakukan deteksi tumbuh kembang dan pemeriksaan kesehatan berkala bagi anak penyandang disabilitas tersebut.
\end{abstract}

Kata Kunci : anak disabilitas, pendampingan, tumbuh kembang 


\section{PENDAHULUAN}

Anak-anak penyandang disabilitas adalah anggota masyarakat yang paling rentan. Mereka berpeluang untuk memperoleh manfaat dari langkah-langkah untuk memperhitungkan mereka, melindungi mereka dari penyalahgunaan dan menjamin mereka memiliki akses pada keadilan. Di berbagai Negara, respon terhadap anak disabilitas umumnya terbatas pada institusionalisasi, ditinggalkan atau ditelantarkan.

Anak-anak disablitas seringkali dianggap rendah, diskriminasi karena disabilitas berujung pada marginalisasi dari sumber daya dari sumber daya bahkan pada kematian anak. Berdasarkan data di Kelurahan Talagasari Kecamatan Kawalu Kota Tasikmalaya, anak penyandang disabilitas berjumlah sekitar 141 orang dengan berbagai keterbatasan. Hal ini tentu saja memerlukan penanganan khusus agar anak tetap memiliki kualitas hidup yang tinggi dan dapat diterima di masyarakat. Upaya-upaya penanganan terhadap anak disabilitas sudah dilakukan oleh Badan Rehabilitasi berbasis masyarakat yang banyak berperan serta secara aktif dalam memfokuskan perhatian pada anak penyandang disabilitas ini.

\section{METODE}

Metode kegiatan adalah Pelatihan dengan metode ceramah, tanya jawab, diskusi, demontrasi, simulasi dan melakukan pemeriksaan kesehatan dan tumbuh kembang dalam upaya peningkatan kualitas anak disabilitas. Kegiatan telah dilaksanakan pada mulai bulan Agustus dan September 2018 yang bertempat di wilayah Kelurahan Talagasari Kecamatan Kawalu Kota Tasikmalaya.

\section{III.HASIL DAN PEMBAHASAN}

Lokasi kegiatan dilaksanakan di RBM Desa Talagasari Kecamatan Kawalu Kota Tasikmalaya dengan sasaran keluarga yang memiliki anak disabilitas sebanyak 33 keluarga

\section{Langkah-langkah Kegiatan}
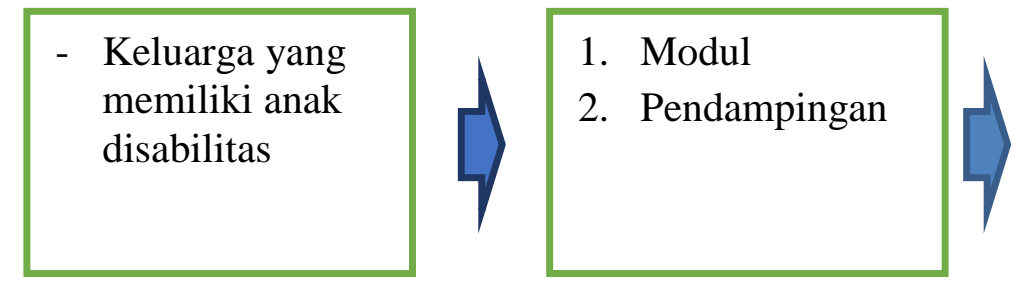

- Pengetahuan keluarga dalam perawatan anak disabilitas meningkat

- Tumbuh kembang anak terpantau

Tabel 1.

Gambaran karakteristik anak disabilitas di Wilayah Desa Talagasari Kecamatan Kawalu Kota Tasikmalaya

\begin{tabular}{lcc}
\hline \multirow{2}{*}{ Variabel } & \multicolumn{2}{c}{ Jumlah } \\
\cline { 2 - 3 } & $\mathbf{N}$ & \% \\
\hline Tuna Grahita & 3 & 11.5 \\
\hline Tuna Rungu + Tuna wicara & 1 & 3,8 \\
\hline Tuna Wicara & 4 & 15,38 \\
\hline Tuna Daksa & 4 & 15,38 \\
\hline Epilepsi & 4 & 15,38 \\
\hline Tuna netra+Kejang+Tdk bisa berjalan & 1 & 3,8 \\
\hline Cerebral Palsy + Kejang & 1 & 3,8 \\
\hline Cerebral Palsy + Autis & 1 & 3,8 \\
\hline Pertumbuhan Terhambat & 1 & 3,8 \\
\hline Gangguan Motorik Kasar + Susah bicara & 1 & 3,8 \\
\hline Keterlambatan Belajar & 1 & 15,38 \\
\hline Down Syndrom & 4 & 100 \\
\hline Jumlah Total & 26 & \\
\hline
\end{tabular}


Berdasarkan tabel di atas, di desa Talagasari Kecamatan Kawalu keadaan disabilitas terbanyak adalah anak dengan tuna wicara, tuna daksa, epilepsy dan down syndrome.

Tabel 2

Gambaran Pengetahuan Keluarga tentang cara perawatan anak disabilitas

\begin{tabular}{lccc}
\hline \multicolumn{1}{c}{ Variabel } & Mean & Min - maks & 95\% CI \\
\hline Pre Test & 60,5 & $26-86$ & \\
\hline Post Test & 92 & $60-100$ & \\
\hline
\end{tabular}

Dari tabel di atas dapat dilihat bahwa hasil post test secara signifikan mengalami peningkatan yang signifikan dari pre test. Hal ini dimungkinkan karena masyarakat sudah mendapatkan pencerahan dan tambahan pengetahuan.

Berdasarkan hasil pre dan post test didapatkan klasifikasi pengetahuan masyarakat sebagai berikut:

Tabel 3

Klasifikasi Pengetahuan Keluarga berdasarkan evaluasi yang dilakukan

\begin{tabular}{lcccc}
\hline \multicolumn{1}{c}{ Klasifikasi } & \multicolumn{2}{c}{ Pretest } & \multicolumn{2}{c}{ Post-test } \\
\hline Baik & $\mathrm{N}$ & $\%$ & $\mathrm{~N}$ & $\%$ \\
\hline Cukup & 8 & 34,79 & 15 & 65,21 \\
\hline Kurang & 7 & 30,42 & 8 & 34,79 \\
\hline Jumlah & 8 & 34,79 & - & 0 \\
\hline
\end{tabular}

Dari tabel di atas dapat dilihat adanya perbedaan tingkat pengetahuan dari responden dimana pada pelaksanaan post test

Adapun penilaian untuk menilai keberhasilan adalah:, responden lebih banyak ada pada klasifikasi pengetahuan baik.

- Dari segi partisipasi keluarga disabilitas, sebagian besar keluarga hadir pada kegiatan yang diselenggarakan diantaranya pemberian materi dan diskusi, sedangkan pada kegiatan deteksi perkembangan keluarga yang berpartisipasi sedikit. Hal ini disebabkan karena adanya kesalahan dalam menyampaikan informasi pada para peserta sehingga deteksi perkembangan akan dilakukan kembali pada kegiatan yang akan datang.

- Terjadi peningkatan kognitif yang ditandai dengan peningkatan pengetahuan tentang materimateri yang sudah disampaikan serta hasil pre dan post test

- Adanya antusiasme dari para peserta dalam mengikuti kegiatan yang diselenggarakan.

\section{Faktor Pendukung dan Kendala}

Faktor pendukung dalam pelaksanaan kegiatan antara lain dukungan Ketua RBM dan tokoh masyarakat sangat mendukung kegiatan karena kegiatan sangat dibutuhkan oleh masyarakat saat ini.

Kedala yang ditemui selama pelaksanaan kegiatan adalah dalam hal komunikasi penyampaian informasi, terkadang terkendala

\section{Program Tindak Lanjut}

Setelah pelaksanaan kegiatan pelatihan pendampingan pada keluarga disabilitas, penulis menyusun program tindak lanjut yang akan dilaksanakan pada kegiatan pengabdian masyarakat di tahun berikutnya. Adapun program tindak lanjut yang akan dilakukan adalah:

- Pemantauan tumbuh kembang dan status kesehatan anak disabilitas

- Pemantauan bimbingan antisipasi yang dilakukan keluarga yang memiliki anak disabilitas

- Tingkat kemandirian anak disabilitas 


\section{IV.SIMPULAN}

Setelah dilakukan pendidikan kesehatan dan pendampingan pada keluarga disabilitas di wilayah Desa Talagasari Kecamatan Kawalu Kota Tasikmalaya, ada beberapa hal yang dapat disimpulkan yaitu:

1. Partispasi keluarga yang hadir cukup antusias dari setiap kegiatan yang dilakukan.

2. Terjadi peningkatan. pengetahuan dari nilai pre dan post yaitu untuk kader kecil dimana rata-rata nilai pre test 60,5 menjadi 92 untuk rata-rata nilai post test.

3. Terdapat adanya data peningkatan peran serta keluarga

\section{DAFTAR PUSTAKA}

1. Direktorat Riset dan Pengabdian Kepada Masyarakat. (2017). Panduan Pelaksanaan Penelitian dan Pengabdian Kepada Masyarakat di Perguruan Tinggi. Edisi XI. Jakarta

2. Hockenberry, M., and Wilson,D. (2009). Buku Ajar Keperawatan Pediatrik. Volume 1. Jakarta: EGC

3. Kementerian Kesehatan RI. (2010). Petunjuk Teknis Standar Pelayanan Minimal Bidang Kesehatan Di Kabupaten/Kota. http://bankdata.depkes.go.id

4. UNICEF. (2013). Keadaan Anak di Dunia: Rangkuman Eksekutif. 
